УДК 811.11-112

DOI: $10.18384 / 2310-712 X-2015-4-14-23$

\author{
Ахренова НА. \\ Московский государственный областной социально-гуманитарный институт
}

\title{
ОСОБЕННОСТИ ДИСКУРСА FАSНION-БЛОГОВ
}

Аннотация. Данная статья посвящена изучению нового для русскоязычного сегмента блогосферы интернета и устоявшегося в англоязычной блогосфере феномена - fashionблогинга. Fashion-блоги рассматриваются как дискурс, как комплексное многогранное явление, что определяет изучение как лингвистической, так и экстралингвистической компонент данного дискурса. В статье обобщается имеющийся теоретический материал, посвящённый блогам; даётся определение fashion-блога; описываются особенности именования блогеров, структура fashion-блога и блог-поста, лингвистические особенности fashion-блогов. Все положения проиллюстрированы примерами из блогов популярных fashion-блогеров.

Ключевые слова: блог, fashion-блог, структура fashion-блога, дискурс, описательное прилагательное, аллюзия, метафора, ирония, игра слов.

\section{N. Akhrenova \\ Moscow State Region Institute of Humanities and Social Studies \\ THE PECULIARITIES OF FASHION-BLOGS DISCOURSE}

Abstract. The article is devoted to the research of fashion-blogging in Russian and Englishspeaking blogospheres. Fashion-blogs are regarded as a type of discourse, as a complex versatile phenomenon. In accordance with this approach both linguistic and extra-linguistic factors should be taken into consideration. In the article an overview of the theoretic material devoted to blogs is given; peculiarities of fashion-bloggers' names, the structure and linguistic characteristics of fashion-blogs and blog-posts are described. All the points are illustrated by unique and fresh examples from popular Russian and English-speaking bloggers.

Key words: blog, fashion-blog, structure of fashion-blog, discourse, descriptive adjective, allusion, metaphor, irony, word play.

Интернет как информационно-социальное явление более двадцати лет оказывает существенное влияние на все сферы человеческой жизни: межличностное общение, совершение покупок, просмотр фильмов, чтение, обучение и т.д. Под влиянием Интернета формируется мнение его пользователей об окружающем мире, о том, какие фильмы и театральные постановки смо-

(C) Ахренова Н.А., 2015. треть, какие книги и журналы читать, какую пищу есть, что носить. С одной стороны, информационное изобилие избавляет от проблемы выбора, с другой - мнение людей и они сами попадают в зависимость от глобальной «машины» манипулирования. Основными блоками этой «машины» можно считать интернет-СМИ, социальные сети, виртуальные сообщества и, конечно, блоги различной тематической направлен- 
ности (образование, политика, путешествия, мода, искусство, общество).

Общеизвестно, что блог (сокращение от web log) чаще всего определяется как интернет-дневник, персональный хронологический журнал размышлений автора-блогера, публикуемый на веб-странице. На сегодняшний день в мировой сети существует более пятидесяти миллионов блогов, а в Рунете действует более миллиона двухсот тысяч блогов. Структурно блог состоит из основного сообщения (поста), вокруг которого разворачивается дискуссия, и комментариев к нему [1].

Блоги различаются по типу контента, содержащемуся в нём. Принято выделять текстовые блоги (содержат в основном текстовые посты), фотоблоги (содержат авторские фотографии), арт-блоги (блог художников, где выкладываются работы авторов и пишутся комментарии к ним), музыкальные блоги (блоги, созданные на платформе MySpace, Soundcloud, основной контент которых нередко составляет музыка собственного сочинения и исполнения), блоги на основе подкастов (блоги, содержащие, например, радиотрансляции), видеоблоги (создаются на платформе Youtube и Vine).

Говоря о блогах, необходимо упомянуть об особенностях содержания (контента) блогов. Принято выделять: 1) контентные блоги с авторскими заметками (постами); 2) мониторинговые, состоящие из ссылок на другие сайты и комментарии; 3) цитатные, построенные на перепостах из других блогов; 4) сплоги, в которых контент формируется автоматически с помощью RSS и других блогов, в расчёте на верхние строчки в поисковых машинах [16].
Говоря о технических характеристиках блогов, необходимо отметить самостоятельные блоги (stand-alone blogs), которые имеют самостоятельный «движок» с доменным именем второго уровня, и блоги на блоговой платформе, характеризующиеся доменным именем третьего уровня, не требующих затрат времени и средств на техническую сторону ведения блога, что даёт возможность выбрать интерфейс из большого количества шаблонов и тем. Самостоятельные блоги доступны коммерчески успешным блогерам [17].

Исследование аутсорсинговой компании IgniteSpot выделяет ещё пять типов блогеров, исходя из намерения получать прибыль от блога [22]:

1) специалист частичной занятости (использует блогинг для дополнительного заработка);

2) любитель (не использует блогинг для прибыли, 60 \% любителей проводят в этом процессе менее 3 часов в неделю);

3) специалист полной занятости (блогинг как работа);

4) корпоративный блогер (занимается ведением блога конкретной организации либо в дополнение к своим основным обязанностям, либо это его единственная задача);

5) предприниматель (ведёт блог для своей компании, такие блогеры составляют $13 \%$ от общего числа).

Необходимо отметить, что серьёзные блогеры [7], оказывающие заметное влияние своими публикациями на умы пользователей, имеют большое количество зарегистрированных постоянных читателей (фоловеров, от английского follower - последователь), пользуются авторитетом как у постоянных посетителей, так и среди рекла- 
модателей, представителей крупного бизнеса, политиков, режиссёров театра и кино. Последние часто прибегают к помощи блогеров для продвижения своих брендов, книг, журналов, спектаклей, фильмов и т.д.

В данной статье рассматривается дискурс fashion-блогов. Следует отметить, что до недавних пор такого феномена, как fashion-блог, не существовало. Ранее, чтобы получить «имя» в мире критики индустрии моды, нужно было иметь многолетний опыт работы в этой сфере и / или соответствующее образование.

Интернет в целом и блогосфера в частности в корне поменяли ситуацию. Благодаря плюрализму мнений и суждений, выражаемых в сети, посты fashion-блогеров были замечены сначала рядовыми пользователями интернета, а уже потом дизайнерами и крупными модными домами. Для западного мира моды fashion-блогеры уже давно перешли в разряд журналистов или модных критиков, стали неотъемлемой частью модных показов, одним из ключевых элементов продвижения брендов на рынке. Дизайнеры и модельеры готовы платить крупные гонорары за положительный отзыв об их коллекции или бренде.

В то время как за рубежом говорят о закате fashion-блогинга, о чём в интернет-версии журнала «The Cut» в 2014 г. пишет Робин Гивхен в статье «The Golden Era of 'Fashion Blogging' Is Over» [21], в российском сегменте интернета fashion-блог находится на начальной стадии своего становления, во многом копируя зарубежные аналоги, что отражено и в их структуре, и в составе языка. Этот факт подтверждается тем, что первый рейтинг русско- язычных fashion-блогеров появился лишь в 2013 г. на сайте TrendSpace [13].

Fashion-блог - журнал записей, связанных с модой, стилем, одеждой с точки зрения их смыслового наполнения. Он призван освещать стиль жизни (lifestyle) блогера, имеющий своей целью скрыто рекламировать, «программировать» подписчиков (фоловеров) на покупку в определённых магазинах и торговых центрах косметики, аксессуаров, одежды определённых брэндов и дизайнеров, а также ездить отдыхать по рекомендуемым маршрутам, слушать музыку нужных рекламодателю музыкальных направлений, читать произведения определённых авторов, посещать выставки.

Основным типом контента такого блога являются посты о современной моде, публикации, в которых блогеры рассказывают о последних событиях в этой области, выкладывают фотографии с показов одежды на неделях моды (fashion weeks), рассказывают о том, что нужно носить в текущий сезон, а также выкладывают собственные фотографии (так называемые looks - луки или образы), где подробно описывают, какой марки одежда, где куплена, её стоимость, и объясняют, почему вещи лучше сочетать именно таким образом.

Мы убеждены, что, говоря о fashion-блогах как о многогранном феномене, их необходимо рассматривать именно как дискурс, а не как жанр или стиль. Это связано с тем, что дискурс понятие более широкое, связанное не только с лингвистическими характеристиками текстов, рождённых в блогах, но скорее с целым спектром экстралингвистических параметров, которые участвуют в создании особой 
атмосферы fashion-блогов. Проводя описание fashion-блогов, необходимо учитывать все его составляющие: имена блогеров, их профессию, круг интересов, те посты, которые они создают, ссылки, которыми делятся, структуру блог-постов и, конечно, лингвистические и стилистические средства, которые определяют этот уникальный мир. Наши предположения подтверждаются определением дискурса, данным в Лингвистическом энциклопедическом словаре: «... связный текст в совокупности с экстралингвистическими прагматическими, социокультурными, психологическими и другими факторами; текст, взятый в событийном аспекте $<\ldots>$, речь, рассматриваемая как целенаправленное социальное действие, как компонент, участвующий во взаимодействии людей и механизмах их сознания (когнитивных процессах). Дискурс - это речь, «погружённая в жизнь» [11]. Во вступительной статье к русскоязычному изданию работы Т. ван Дейка Ю.Н. Караулов и В.В. Петров аккумулировали его воззрения: «Дискурс - это сложное коммуникативное явление, включающее кроме текста ещё и экстралингвистические факторы (знания о мире, мнения, установки, цели адресанта), необходимые для понимания текста [8, с. 8].

Описание рассматриваемого дискурса необходимо начать с портрета его главного персонажа - типичного fashion-блогера. Можно выделить два типа: 1) тот, кто описывает только модные тенденции в одежде и аксессуарах, периодически делится своими впечатлениями о походах за покупками в различных торговых центрах; 2) тот, кто помимо своих фотографий и рассказа о модных тенденциях в одеж- де различных брендов выкладывает фотографии и статьи о пресс-турах, модных показах, презентациях, рекламирует конкурсы, проводимые известными брендами, в компаниях которых участвуют блогеры; размещает статьи о моде и модных тенденциях, как свои, так и других авторов. Блогеры первого типа обычно ведут свои блоги на различных блоговых платформах, таких как blogspot.ru, lifejournal.com. Блогеры второго типа организуют свой блог на самостоятельном «движке» с доменным именем второго уровня. Часто блогеры второго типа превращают традиционный блог в модный портал, подобный интернет-версиям авторитетных глянцевых журналов (L'Officiel, $E L L E$ и т.д.). Примерами блогов первого типа являются блоги Сьюзан Баббл [23], Елены Ленц [10], Брайн Бой [20] и т. д. К блогам второго типа можно отнести блоги Екатерины Василенко [3], Маги [12], Анны Русска [14] и т.д. Тип платформы, на которой создан блог и его формат, зависит, на наш взгляд, не только от масштабов финансирования работы блогера, но и от желания, точнее, необходимости, быть со своим читателем на равных, быть близким и понятным ему. Это необходимо ещё и для того, чтобы им доверяли не только представители элиты общества и завсегдатаи модных показов, но и обыватели, которые в поисках своего уникального стиля исследуют информационное пространство интернета или хотят ознакомиться с основными модными тенденциями предстоящего сезона.

Абсолютное большинство аудитории блогеров не имеют непосредственного отношения к миру моды. Это студенты, домохозяйки, подрост- 
ки, работники бюджетной сферы и т.д. Многие не имеют финансовой возможности пополнять свой гардероб в магазинах тех дизайнеров, наряды которых они рассматривают на фотографиях владельцев блогов. Особенно это касается аудитории русскоязычных fashion-блогов, так как у нас не развита культура брэндовых аутлетов, где можно недорого купить вещи из прошлых коллекций модных дизайнеров. Ситуация с западными fashion-блогерами коренным образом отличается от российских. Этим, на наш взгляд, объясняется большое количество постов блогеров, посвящённых сетевым магазинам, рассчитанным на покупателей со средним уровнем дохода.

Проанализировав ряд модных блогов, мы можем с уверенностью сказать, что типичный fashion-блогер - это персонаж женского пола (признанных мужчин fashion-блогеров всего 4 человека), который работает или работал в индустрии моды (профессии могут варьироваться: фотограф, модель, автор рекламных компаний известных модных брендов, визажист, стилист, фэшнредактор и т.д.), сотрудничающий со многими модными изданиями, часто уровня Cosmopolitan, ELLE, L'Officiel, Vogue, и дизайнерами. Ряд блогеров сотрудничают с PR-службами; нередко живут за границей (Жанна Ромашка [19], Мага [12], Либертин [24], Кукла Маша [13] и т.д.); имеют свой он-лайни / или офф-лайн-магазин одежды и аксессуаров, которые они продвигают при помощи своего блога.

Блогеры могут работать как используя своё реальное имя (Виктория Платина [13], Ульяна Ким [13], Дарья Куниловская [9], Александр Рогов [13]), так и под псевдонимами (никами) [6].
Можно предположить, что многие fashion-блогеры, особенно считающиеся авторитетными журналистами и модными критиками, сделали взятый однажды псевдоним своей реальной фамилией и на вопросы журналистов отвечают, что это их настоящие фамилии. Яркими примерами можно считать блогеров Анну Брейн [13] и Анну Русска [14].

К тенденциям именования блогеров можно отнести сохранение реального имени и фамилии, а также использование сокращённой, более интимной, домашней формы имени, например: Катя Бутко [13], Саша Федорова [13], Паша Бобров [13], Наташа Туровникова [13], Оля Калаева [13], Рита Галкина [13].

Обладатели звучных имён называют себя только по имени, например: Власта - Власта София Гурьева (Vlasta Sophia Guryeva) [4], Maza - Maza (Магамед) Умхаев [12].

Многие блогеры работают под псевдонимами. Псевдонимы могут быть разделены на три подгруппы.

1. Прежде всего необходимо отметить подгруппу эквицентрических прозвищ, в которых антропонимический и нарицательный компоненты имеют более или менее одинаковое смысловое значение. Антропоцентрический элемент обычно представлен одним из подлинных имён человека и является, безусловно, главным индивидуализатором, а нарицательный элемент характеризует его по какимлибо внешним или деятельностным признакам. Яркими примерами можно считать имена таких популярных блогеров, как Brian Boy (Брайан Грей Ямбао) [20], Suzy Babble (Susanna Lau) [23], Жанна Ромашка (Zhanna Bianka) 
[19], Кукла Маша (Мария Колосова) [13], Евгения Эплбум (Eugenia Applebum) [5], Masha Ysi-Pusi (Маша Новикова) [13] и т.д.

2. Ко второй подгруппе можно отнести псевдонимы, представляющие собой слова-гибриды (blends), состоящие из частей имени и фамилии блогера, например: Белоника - Белоцерковская Ника [13], Либертин - Либерман Татьяна [24].

3. К третьей группе можно отнести яркие названия, которыми пользуются блогеры - владельцы модных порталов: Only Stylish People (Жанна Ромашка) [19], shmotomodo (Екатерина Василенко (Орлеана)) [3], Man Repeller (Леандра Медин (Leandra Medin)) [25], Style Bubble [23], Журнал abolenkin [13], Fashion Daily (Дарья Куниловская) [9], Sofie goes Around (Власта) [4], Sofie Aveпие (София Елисеева) [13], Cherry Blossom Girl (француженка, проживающая сейчас в Японии, по имени Аликс) [18], «Каждый модныци день» (Дарья Куниловская) [9]. Полагаем, что эти названия можно считать своеобразными никами, так как на их авторов часто ссылаются, указывая не их реальные имена, а названия их блогов.

Рассмотрев блоги более подробно, можно выделить их общие структурные особенности. Любой fashion-блог, как и блог обыкновенный, состоит из главной страницы, где расположена лента новых публикаций, информация об авторе (авторах) блога, архив постов блога, ссылки на страницы блогера в социальных сетях, а также контакты. Многие ведут видеоблог обучающего характера. Каждый пост содержит положительные и / или отрицательные комментарии читателей. Для комментирования необходимо зарегистриро- ваться в блоге, т.е. стать подписчиком. Обязательной составляющей любого блога, как самостоятельного, так и на блоговой платформе, можно считать архив фотографий модных показов, походов за покупками и путешествий, каталог полезных ссылок, а также часто указываются цены и марки вещей, которые были надеты на блогере во время фотосессии или описаны в посте.

Рассматривая структуру поста в блоге, можно наблюдать заметное сходство в его строении с рекламной статьёй в журналах, газетах и интернет-СМИ.

Пост в блоге характеризуется ёмкими, короткими, иногда парадоксальными заголовками, часто обыгрывающими крылатые фразы, содержат цифры (даты), например: Spring is in the air (Love is in the air... John Paul Young (1978)); Пуховик неизбежности (по аналогии с «Психологией неизбежности», использован каламбур, чтобы подчеркнуть необходимость пуховика в гардеробе каждой женщины), The Difference Between Mom Jeans and Dad Jeans; To Go Home or Not To Go Home? That is the Question ("To be, or not to be: that is the question" (William Shakespeare. "Hamlet")).

В стандартных печатных рекламных статьях абзацы в основной части разделяются подзагаловками. В блогпостах чаще на месте подзаголовков можно встретить фотографии авторов в описываемых вещах и интерьерах.

Общепризнанно, что сегодня основным типом чтения является просмотровое, когда читают с целью получить общее представление о содержании текста, о теме и круге рассматриваемых в нём вопросов. Про- 
смотрев текст, читатель принимает решение, нужно ли ему читать текст более внимательно, нужна и важна ли ему эта информация. Причиной такого изменения стало значительное увеличение потока информации, который должен воспринимать современный человек.

Поэтому крайне важной задачей для блогеров становится размещение в постах качественных тематических изображений, иллюстраций, которые описываются в тексте. Посты организованы таким образом, что могут привлечь читателей разных типов: аудиалов и кинестетиков; например: «С другой сторонь аромать - не только секс. Разучивиись фантазировать, мь оказались неспособными усльичать дыхание, биение крыльев, дождь или любовь в запахе. А как иногда прекрасно пахнуть сумерками в августовском Риме вместо банального «иветочно», «сладко» и «жасминово»! В чём разница? В голове.» [12]; «Я люблю особенно макси летом. Они должнь былть лёгкими и ткань должна струиться при каждом шаге. Мои любимье Candy's nросто читают женские мьсли. Платье макси с иветочным принтом, открытыми плечами просто волшебно вьглядит и при малейием порьве ветра очень красиво взлетает, идёиь такая, как фея.»[15]. В этих описаниях преобладает яркая образность.

Исследование блогов позволяет выделить их следующие лингвистические характеристики:

1) Тексты fashion-постов отличаются высокой экспрессивностью благодаря использованию большого количества описательных прилагательных, часто в превосходной степени. Чтобы подчеркнуть центральное для блогера качество предмета, прилагательные редуплицируются (данный приём характерен для интернет-дискурса). Также для этой цели могут использоваться усиливающие значение прилагательных наречия степени (very, too, so), восклицательные предложения; значимые слова пишутся заглавными буквами, используются невербальные средства, характерные для интернет-коммуникации - эмотиконы (“смайлики»), нередко заменяющие знаки препинания, например: "In true Marc Jacobs fashion, the pockets are huge, the buttons are big AND extremely shiny. The fabrics are of the highest quality; thick, heavy and rich, rich, rich!", "know you'll be wearing them for a long, very long, time." [20]; “Доброе утро, дорогиец У нас такая насыменная программа мероприятици, встреч и вечеринок, что кажется я перестала ориентироваться в датах, числах $и$ днях недели))) Но это здорово, не представляю как вернусь домой после такого круговорота собъьтий)))." [5].

2) Для облегчения восприятия текста поста, носящего рекламный характер, не используются сложносочиненные предложения, ср.: «И так, я приехала довольно рано, в будний день. Это всегда лучшее время для шоппинга, запомните!) Дикой жарь не бьло, да и людей практически тоже. По всей территории аутлета играет приятная музыка. Никакого ошушения бешеного ритма, толкучки или того, что срочно нужно что-то купить. Меня это сразу расположило к приятному времяпрепровождению. Захотелось просто купить что-то для себя, удовольствия padu.» [10]; "Go for a slouchy linen trouser, a great white tunic, and throw your paisley on top like it's psychedelic icing. Don't forget 
the hat, if not to broaden your shade, then to broaden your horizon." [25]; "Chitose Abe needs no introduction. I've been keeping track of her stellar rise over the past few years. With her much-lauded label Sacai on every cool girl's IT-list, a new book that was published by Rizzoli AND a collaboration with Nike under her belt, Chitose is the toast of the town. She's everywhere!" [20].

3) Чтобы быть более понятными и близкими своему читателю, блогеры используют слова, относящиеся к разговорной лексике, например: but y'all know me..., wanna, I'm not gonna lie..., they're NOT gonna last very long but man oh man, Hanging out with my erm... excuse the un-PC term... "gaysian" friends has taught me one or two things about Grindr [23]; mpaтumь уймy времени, носибельность / носибельная / ноские, «я присмотрела парочку для своего гардероба» [15], «...застала её аж два раза и в Кисловодске, и в СанктПетербурге)» [5].

4) В англоязычных блогах преобладают заимствования из французского языка (the Patrouille de France [20]; l'oeil BA collection [23]), относящиеся к тематическому полю мода и стиль.

5) В русскоязычных блогах присутствуют заимствования из английского и французского языков, часто только транслитерированные на русский язык ( «... не comme il fault для модника - так примитивно мьстить» [10], аутфит (outfit), ивент (event), бренд (brand), cem (set), кроn-mon (crop-top), тренд (trend), лук (look), лукбук (lookbook), nocm (post), макси (maxi), дизайнер (designer) (дизайнерь,, дизайнерского бутика, дизайнерский), бутик (bоиtique), парфюм (perfume), глосс (gloss)), которые склоняются и спрягаются по правилам русского языка («кутюрное производство» [9], «в иоу-руме», «я полюбила шоу-румы» [2]), хотя могут быть приведены на языке оригинала, например: lookax/oв/e.

Посты блогов богаты на стилистические приёмы, что делает их особенно афористичными и образными; напримep:

1) аллюзии на дизайнеров (Джанни Версаче, Игорь Чапурин), актёров (Дайян Крюгер, Шэрон Стоун, Дженнибер Энистон, Анджелина Джоли, Марлон Бранд и Джеймс Дин), редакторов модных журналов (Франка Социяани (Voguе Italy)), известных моделей (Наоми Кэмnбелл, Наталья Водянова), писателей (Теодор Драйзер, Вера Лендорф, Стебан Цвейг, Коддингтон Грейс), модные бренды (Emporio Armani, Marc Jacobs, Michael Kors), магазины (Outlet Village Белая Дача, Тор Shop, шоурум LILU) и т.д.;

2) метафоры: "My main man, Marc Jacobs, has been killing it (and mind you, killing my finances) lately. A total runway look» [20];

3) эпитеты: Темнокожая пантера; Даже идеально подобранные между собой вещи часто создают довольно скучный и неинтересный союз [2];

4) пословицы: Дьявол обитает в мелочах [2];

5) ирония: "Have they invented the ability to be able to split one's body in two and be in multiple places at one time yet? No? That's my pressing question for Silicon Valley peeps to ponder over in the near future. Seeing graduate collections, more so than established designers, takes a fair amount of in-person vision because you're trying to understand a something you've not seen before and grasp at what might the designer be thinking." [23]; "Another short trip notched up in New York meant another trip to Paintbox, not with palm trees, pine- 
apples or other emoji-esque motifs that are so de rigueur of summer manicures." [23];

6) слова, принадлежащие к высокому литературному стилю: fabulous, magnificent, pretentious, poetic, to flourish, утилитарныцй, неземной, синь, лазурь;

Следует отметить, что многие блогеры с русскоязычными корнями ведут блоги на английском языке или пишут заголовки на английском языке, желая привлечь более широкую зарубежную аудиторию и следовать моде на всё «заграничное». Многие зарубежные блогеры ведут свои блоги на двух языках, например, на английском и французском, как это делает Alix [18].

В конце поста блогеры декларируют выводы, которые освобождают читателя от самостоятельного осмысления информации, что играет решающую роль в формировании мнения читателя. Выводы часто косвенные, а не прямые, обязательно содержат побуждение к действию: «Bom наш девиз! При помощи Asos.com можно с минимальньми затратами времени, сидя за ноутбуком с бокалом освенающего лимонада, заказать понравивиийся аутфит и никакой беготни по магазинам. Желаю приятных покупок!» [15]; «Конечно, это не все мои находки! Но самими главными я с вами уж точно поделилась. Обязательно поеду, как только выдастся денёк, туда ещё раз. Даже чтобы просто погулять и отдохнуть от городской суеть. Ну и конечно, чтобь что-то прикупить)» [10]; "Wanna know what I need to serve as an exclamation mark to this lewk? The olive green ostrich leather bag Marc named after me. Such a shame that bag is in the Philippines at the moment. I'll make it my priority to get it the next time I go back to visit family." [20].
Подводя итоги проведённого исследования, хотелось бы отметить, что оно представляет собой первый опыт рассмотрения дискурса fadhion-блогов с позиций лингвистики, социолингвистики, исследования манипулятивных технологий в текстах подобного жанра. Перспективами изучения дискурса fashion-блогов является рассмотрение таких аспектов, как гендерные различия в поведении fashion-блогеров и семантические поля в fashion-блогах.

\section{ЛИТЕРАТУРА:}

1. Блог // Википедия - свободная энциклопедия. 2015. [Электронный ресурс]. URL: https://ru.wikipedia.org/wiki/Блог (дата обращения: 22.06.2015).

2. Булгакова Ирина. My Lookbook. [Электронный pecypc]. URL: http:// irinabulgakova.blogspot.nl/ (дата обращения: 27.06.2015).

3. Василенко Екатерина. Личный блог. [Электронный ресурc]. URL: http:// shmotomodo.ru/ (дата обращения: 27.06.2015).

4. Власта. Личный блог. [Электронный pecypc]. URL: http://sofiegoesaround. com/ (дата обращения: 27.06.2015).

5. Евгения Эплбум. Личный блог. [Электронный ресурc]. URL: http://applebum. $\mathrm{ru/}$ (дата обращения: 27.06.2015).

6. Ермолович Д.И. Имена собственные на стыке языков и культур. М.: Р. Валент, 2001. 200 c.

7. Жукова Ольга. Самые известные модные блоггеры в России и в мире. [Электронный ресурc]. URL: http://www. fashiontime.ru/fashion/reviews/1056131. html (дата обращения: 27.06.2015).

8. Караулов Б.С., Петров В.В. От грамматики текста к когнитивной теории дискурса // Дейк Т.А. ван. Язык. Познание. Коммуникация: Пер. с англ. / Сост. В.В. Петрова; Под ред. В.И. Герасимова; Вступ. ст. Ю.Н. Караулова и В.В. Петрова. М.: Прогресс, 1989. С. 5-11. 
9. Куниловская Дарья. Личный блог. [Электронный pecypc]. URL: http:// fashion-daily.livejournal.com/ (дата обращения: 27.06.2015).

10. Ленц Елена. Личный блог. [Электронный pecypc]. URL: http://elenalentc. blogspot.ru/ (дата обращения: 27.06.2015).

11. Лингвистический энциклопедический словарь / Гл. ред. В.Н. Ярцева. 2-е изд., доп. М.: Большая Российская энциклопедия, 2002. 709 c.

12. Мага. Личный блог. [Электронный ресурс]. URL: http://magamgd.com/ (дата обращения: 27.06.2015).

13. Модные блоггеры России: топ 50. [Электронный ресурc]. URL: http:// www.trendspace.ru/moda/5904/ (дата обращения: 27.06.2015).

14. Русска Анна. Личный блог. [Электронный ресурc]. URL: http://annarusska.ru (дата обращения: 27.06.2015).

15. Сизонова Тина. Личный блог. [Электронный ресурc]. URL: http://www. tinasizonova.com/ (дата обращения: 27.06.2015).

16. Сплог // Википедия - свободная энциклопедия. 2015. [Электронный ресурс]. URL: https://ru.wikipedia.org/wiki/ Сплог (дата обращения: 27.06.2015).

17. Хмелева Х.П. Инструменты создания высокорейтингого фэшн-блога: дипломная работа. М.: МГУ имени М.В. Ломоносова, факультет журналистики. [Электронный ресурс]. URL: $\quad$ https://vernsky.ru/pubs/5794/
Instrumenty_sozdaniya_vysokoreytingovogo_feshn-bloga (дата обращения: 29.06.2015).

18. Alix. Personal blog. [Электронный pecypc]. URL: http://www.thecherryblossomgirl.com/ (дата обращения: 27.06.2015).

19. Bianka Zhanna. Personal blog. [Электронный pecypc]. URL: http:// onlystylishpeople.blogspot.ru/ (дата обращения: 27.06.2015).

20. Bryan Boy. Personal blog. [Электронный pecypc]. URL: http://www.bryanboy. com/ (дата обращения: 27.06.2015).

21. Givehan Robert. The Golden Era of 'Fashion Blogging' Is Over. [Электронный pecypc]. URL: http://nymag.com/thecut/2014/04/ golden-era-of-fashion-blogging-is-over. html (дата обращения: 30.06.2015).

22. Ignite Spot: The blog economy infographic stats. / Outsourcing company. 2014. [Электронный ресурc]. URL:http:// www.social4retail.com/the-blog-economy-blogging-stats-infographic-2014. html (дата обращения: 26.06.2015).

23. Lau Susanna. Personal blog. [Электронный ресурc]. URL: http://www. stylebubble.co.uk/ (дата обращения: 27.06.2015).

24. Libertine. Personal blog. [Электронный pecypc]. URL: http://liebertine.livejournal.com/ (дата обращения: 27.06.2015).

25. Medin Leandra. Personal blog. [Электронный ресурc]. URL: http://www. manrepeller.com/ (дата обращения: 27.06.2015). 